\title{
Incidencia de parto pretérmino y factores de riesgo
}

\author{
Dr. Alvaro Monterrosa Castro*
}

\begin{abstract}
RESUMEN. Para determinar la incidencia y los factores de riesgo de parto pretérmino se estudiaron todas las pacientes que en 1988 tuvieron parto prematuro en el Hospital de Maternidad Rafael Calvo, Cartagena, Colombia. Igual número de pacientes con parto de término fueron colocadas como control. 10.550 partos, 9.787 de término y 763 de pretérmino, establecen una incidencia del $7.3 \%$. La primera causa determinada fue ruptura prematura de membranas (22.9\%) y la segunda, infección urinaria (13.2\%). Hemorragia de segunda mitad de gestación: $14.7 \%$, embarazo múltiple $4.7 \%$.

En adolescentes $\mathrm{Rr}=3$ y mayores de 36 años $\mathrm{Rr}=2$. El $40 \%$ de las pacientes eran primigestantes. Parto prematuro previo $R r=2.8$. Aborto previo $R r=4.5$, falta de control prenatal $R r=8.5$, hábito de fumar $R r=2.2$, actividad laboral materna $R r=$ 1.9. Se hace énfasis en la importancia de determinar la presencia de diversos factores de riesgo para adelantar prevención en el desencadenamiento del trabajo de parto. La prevención es el arma más importante para combatir la prematurez. (Rev Col Obstet Ginecol 1991; 42(3): 199-207).
\end{abstract}

PALABRAS CLAVES: Parto prematuro, adolescentes, hábito de fumar, ruptura prematura de membranas, embarazo múltiple.

SUMMARY. In order to determine the incidence and factors of risk in before schedule childbirth all the patients who suffered premature childbirth in 1988 at the Hospital of Maternidad Rafael Calvo, Cartagena, Colombia, were studied. A similar number of patients with scheduled childbirths, were taken as control. 10.550 childbirth, 9.787 according to schedule and 763 before schedule stablish and incidence of $7.3 \%$. The first cause determine was the premature rupture of membranes (22.9\%) and the second, urinary infection (13.2\%). Hemorrhage during the second half of pregnancy: $14.7 \%$, multiple pregnancy $4.7 \%$.

Adolescents $\mathrm{Rr}=3$ and over 36 year-olds, $\mathrm{Rr}=2.40 \%$ of the patients were first pregnants. Previous prematures childbirth, $R r=2.8$. Previous abortion $R r=4.5$, lack of prebirth control $R r=8.5$, smoking habite $R r=2.2$, mother labor activity $R r=1.9$. Emphasis is made on the importants of determining the presence of diferents factors of risk to improve prevention in the development of the childbirth work. Prevention is the most important means to fight prematureness.

KEY WORDS: Premature labor, adolescents, smoking habite, premature rupture of membranes, multiple pregnancy.

\section{Introducción}

Parto pretérmino es definido como aquel acontecido antes de las 37 semanas de gestación $(1,2)$, y se traduce generalmente en recién nacidos de menos de 2.500 gramos de peso al nacer los cuales con frecuencia tienen graves problemas para la adaptación a la vida extrauterina, sobre todo distress respiratorio $(3,4)$.

El parto pretérmino es la primera causa de morbi-mortalidad perinatal y neonatal $(5,6)$. Cuanto mayor es la prematurez mayor es la mortalidad (1), y los que sobreviven tienen un riesgo significativamente mayor de presentar alteraciones del desarrollo neurológico, con relación a los nacidos de término $(3,7)$.

La frecuencia del parto pretérmino difiere de un centro a otro y ha disminuido donde se han aplicado programas de predicción y prevención $(8,9,10)$. Papiernik $(11,12,13)$ y Creasy $(2,14)$ son autores que han postulado índices para detectar tempranamente aquellas pacientes que desde el comienzo de la gestación están en riesgo de presentar ulteriormente parto pretérmino. Sin embargo los sistemas de prevención han sido cuestionados en su eficacia por algunos autores

\footnotetext{
* Residente III, Departamento de Ginecología y Obstetricia, Facultad de Medicina, Universidad de Cartagena. A.A. 2645.
}

$(15,16)$. La medición seriada de la actividad uterina con modernos monitores ambulatorios son utilizados en la actualidad en centros desarrollados $(17,18,19)$.

La amplia investigación ha permitido definir la existencia de una serie de factores de riesgo para parto pretérmino: nuliparidad (20), adolescencia $(5,21,22)$, desnutrición materno-fetal, deficiente control prenatal $(5,23)$, actividad laboral materna $(24,25,26)$, antecedente de aborto y parto prematuro $(22,27)$, hábito de fumar $(28)$, bajo nivel educativo y social (23), algunas patologías maternas como: diabetes, hipertensión arterial, pielonefritis $(4,6)$, placenta previa y desprendimiento prematuro de placenta $(6,22)$, polihidramnios y embarazo gemelar $(1,4,29,30)$, incompetencia cervical (31), ruptura prematura de membranas $(32,33 ; 34)$, corioamnionitis subclínica $(35,36,37)$, maduración cervical precoz $(8,31)$ e instalación temprana de la actividad uterina $(17,18)$.

La etiología del parto pretérmino es desconocida $(1,2$, 3, 19, 35, 37). Puede suceder: a) Espontáneamente. b) Desencadenado por algunas situaciones, por ejemplo: ruptura prematura de membranas o sobredistensión uterina. c) Inducido, siendo la solución obstétrica a algunas patologías asociadas a la gestación, citemos la hipertensión arterial y la incompatibilidad $\mathrm{Rh}$. d) Iatrogénica a causa de error médico en la medición de la edad gestacional. 
La acción ideal en parto pretérmino no es el uso de medidas generales o farmacológicas para detener el evento $(2,19)$. La prevención es el arma más importante y para conseguirla se deben establecer programas que permitan un mejoramiento socio-económico y educacional de la población. Se hace imprescindible un amplio programa de control prenatal $(5,10,23)$ que implique un servicio de atención médica de muy óptima calidad.

\section{Objetivos}

Determinar la incidencia de parto pretérmino, estableciendo las patologías maternas asociadas, el porcentaje de partos pretérmino espontáneos y conocer qué vía del parto se brinda de acuerdo con la presentación fetal. Precisar la existencia y la significación estadística de factores de riesgo relacionados con edad materna, estado civil, nivel educativo, ocupación del cónyuge, área de procedencia, hábito de fumar, actividad laboral, control prenatal, antecedente de aborto y parto pretérmino, comparándose con los resultados obtenidos en el grupo de parto de término.

En el fruto de la concepción determinar la mortalidad intrauterina, el apgar y la correlación entre edad gestacional y peso al nacer.

\section{Material y método}

Se estudiaron todas las pacientes que teniendo entre 28 y 36 semanas de gestación, tuvieron parto vaginal o fueron sometidas a cesárea en el Hospital de Maternidad Rafael Calvo en Cartagena, Colombia, en 1988. Utilizando la fecha de la última menstruación se calculó la edad gestacional, recurriéndose a ayuda ecográfica en ocasiones y siempre se practicó evaluación confirmatoria en el recién nacido, según el método de Capurro. A cada una de las pacientes se le colocó como control la primera parturienta de término que tuviese igual paridad, con feto en igual presentación y que el nacimiento del producto sucediese por igual vía.

Ambos grupos fueron entrevistados por el investigador, Ilenándose el formulario diseñado para cumplir los objetivos trazados. Los recién nacidos fueron evaluados en la unidad de neonatología. Los resultados fueron tabulados manual-

Tabla 1

\section{INCIDENCIA DE PARTO PRETERMINO Y FACTORES DE RIESGO \\ Patologías Asociadas y Vías del Parto}

\begin{tabular}{|lccr|}
\hline \multirow{2}{*}{ Patologías } & \multicolumn{3}{c|}{ Vía del Parto } \\
& Vaginal & Cesárea & Total \\
\hline Ninguna & 242 & 11 & $253(33.1 \%)$ \\
Ruptura de membrana & 158 & 17 & $175(22.9 \%)$ \\
Infección urinaria & 101 & - & $101(13.2 \%)$ \\
D.P.P.N.I. & - & 66 & $66(8.6 \%)$ \\
Placenta previa & - & 46 & $46(6.1 \%)$ \\
Preeclampsia-Eclampsia & 26 & 20 & $46(6.1 \%)$ \\
Embarazo múltiple & 7 & 29 & $36(4.7 \%)$ \\
Polihidramnios & 17 & - & $17(2.3 \%)$ \\
Amnionitis & 13 & 10 & $23(3.0 \%)$ \\
\hline \multicolumn{1}{|c|}{ TOTAL } & $564(73.9 \%)$ & $199(26.1 \%)$ & $763(100 \%)$ \\
\hline
\end{tabular}

\section{Gráfica 1}

INCIDENCIA DE PARTO PRETERMINO

Y FACTORES DE RIESGO

Distribución por Edades

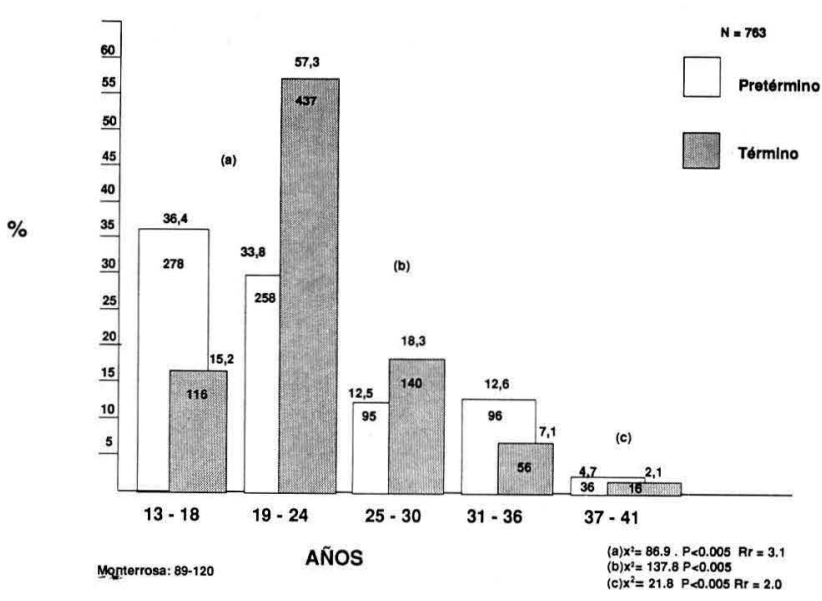

mente y comparados los casos con sus controles. calculándose el riesgo relativo y test de significancia de acuerdo al Chi-cliddrado para los diferentes factores de riesgo.

\section{Resultados}

10.550 partos se presentaron en 1988, siendo 1.825 $(17.3 \%)$ por cesárea y $8.725(82.7 \%)$ por vía vaginal. 763 $(7.3 \%)$ de la totalidad de los partos fueron pretérmino y $9.787(92.7 \%)$ de más de 37 semanas de gestación. El 26.1\% (199) de los embarazos de pretérmino fueron resueltos por cirugía mientras el $73.9 \%$ (564) se obtuvieron por vía vaginal.

De las 763 pacientes pretérmino el $40.8 \%$ (311) tenían entre $31-33$ semanas, el $34.7 \%$ (265) entre $34-36$ semanas $y$ el $24.5 \%$ (187) entre 28-30 semanas. Debió inducirse el parto o practicarse cesárea en 222 pacientes $(29.1 \%$ ) y tuvieron parto pretérmino espontáneamente 541 (70.9\%). La mayoría de estas últimas pacientes consultaron tardíamente no llenando requisitos para realizar inhibición de la actividad uterina, o tenían fetos obitados, por lo que se permitió la expulsión del producto.

El embarazo era único en el 95.3\% (727), 35 (4.6\%) gemelares y un trillizo $(0.1 \%)$, lo que permitió obtener 800 recién nacidos. De ellos $88.5 \%$ (708) nacieron vivos y el $11.5 \%$ (92) habían sufrido muerte intrauterina no pudiéndose determinar en la mayoría la causa del fallecimiento.

PATOLOGIAS ASOCIADAS (Tabla 1). En 253 pacientes $(33.1 \%)$ con parto pretérmino no se encontró patología asociada. La ruptura prematura de membranas fue la entidad más frecuente $(22.9 \%)$, seguida de la infección urinaria $(13.2 \%)$. El manejo obstétrico del desprendimiento prematuro de placenta y de la placenta previa obligó a obtener el $14.7 \%$ de los pretérminos. Sobredistension uterina causó parto prematuro en el $7.0 \%$. Corioamnionitis fue evidenciada clínicamente en el 3.0\%. La misma tabla nos presenta la relación de estas patologías con la vía del parto seleccionada.

FACTORES DE RIESGO

EDAD MATERNA (Gráfica 1). El 36.4\% de las pacientes 
Gráfica 2

INCIDENCIA DE PARTO PRETERMINO Y FACTORES DE RIESGO

Estado Civil

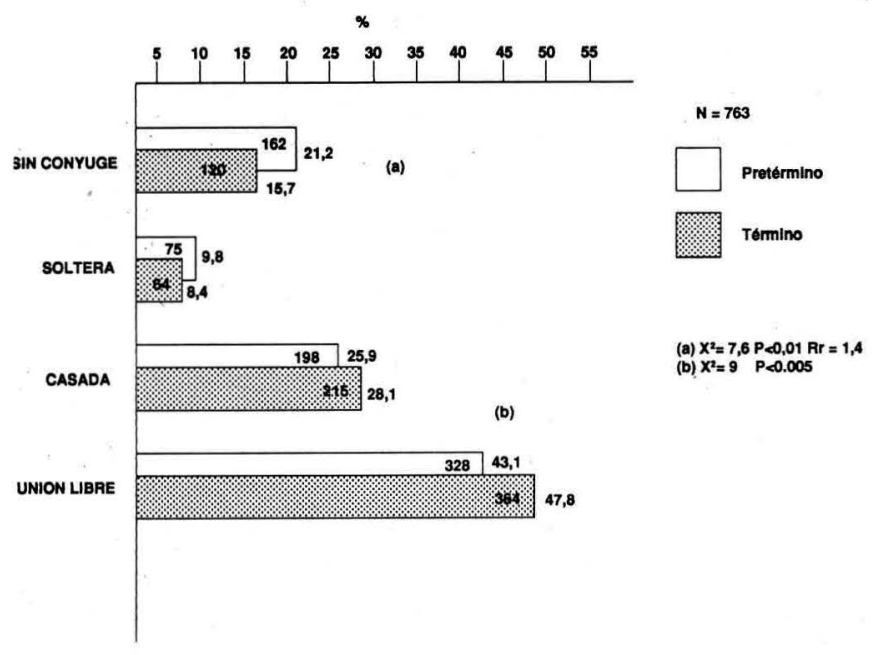

que tuvieron parto pretérmino eran menores de 18 años -siendo el grupo etáreo más frecuente-, mientras el $15.2 \%$ de las gestantes de término tenían igual edad. $X^{2}=89.6$ $\mathrm{P}<\mathrm{Rr}=3.1$. En edades medias de la vida reproductiva (19-30 años) predominaron las pacientes de término $(75.6 \%)$ sobre las de pretérmino $(46.3 \%) . \mathrm{X}^{2}=137.8 \mathrm{P}<0.005$. Sobre 31 años se presentó $17.3 \%$ de los pretérminos y el 9.2\% de los de término. $\mathrm{X}^{2}=21.8 \mathrm{P}<0.005 \mathrm{Rr}=2$.

RESIDENCIA. De las pacientes con parto pretérmino, 512 $(67.1 \%)$ residían en área urbana y 251 (32.9\%) en área rural; de los de término $80.1 \%$ en zona urbana y el $19.9 \%$ en la rural. $\mathrm{X}^{2}=21.8 \mathrm{P}<0.005 \mathrm{Rr}=1.9$.

NIVEL EDUCATIVO. Del grupo de pacientes con parto pretérmino, $83(10.9 \%)$ no sabían leer ni escribir, mientras $680(89.1 \%)$ habían adelantado cursos primarios. Entre los controles, eran analfabetas $67(8.8 \%)$ y alfabetas 696 (91.2\%). $\mathrm{X}^{2}=1.7 \mathrm{P}=$ N.S. $\mathrm{Rr}=1.2$.

\section{Gráfica 3 \\ INCIDENCIA DE PARTO PRETERMINO \\ Y FACTORES DE RIESGO \\ Ocupación del Cónyuge}

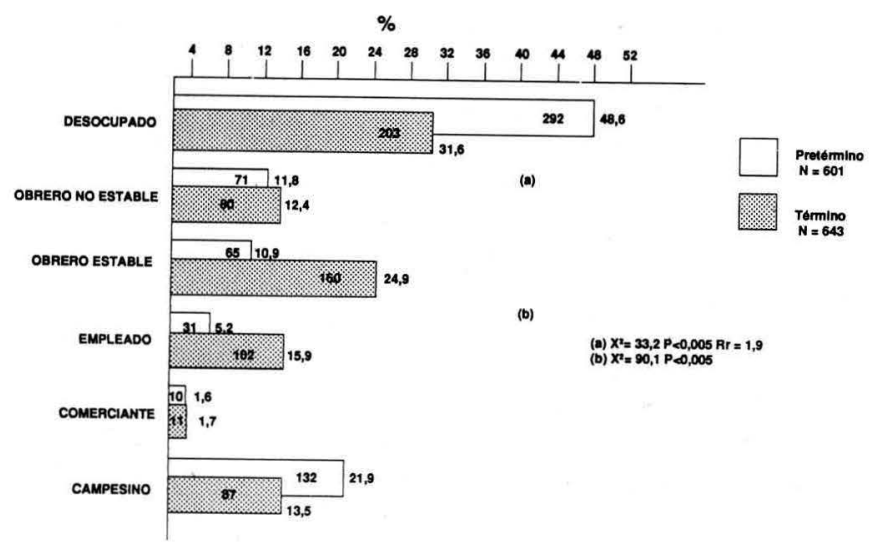

ESTADO CIVIL (Gráfica 2). 21.2\% (162) de las gestantes con parto pretérmino y el $15.7 \%$ (120) de los de término no tenían cónyuge. $\mathrm{X}^{2}=7.6 \mathrm{P}<0.01 \mathrm{Rr}=1.4 .9 .8 \%$ de pretérmino y $8.4 \%$ de término tenían cónyuge pero no estabilidad de hogar (solteras).

Estabilidad de hogar, fuesen casadas o en unión libre, estaban el $69 \%$ de las pacientes con parto prematuro y el $75.9 \%$ de las de término. $\mathrm{X}^{2}=9 \mathrm{P}<0.005$.

ACTIVIDAD LABORAL DEL CÓNYUGE (Gráfica 3). 601 pacientes de parto pretérmino y 643 de término tenían cónyuge. Estos estaban desocupados o no tenían actividad laboral estable en el $60.4 \%$ de las pacientes que tuvieron parto antes de la fecha normal, mientras que en el grupo control acontecía igual situación en el $44.0 \%$ de las pacientes. $\mathrm{X}^{2}=$ 33.2 $\mathrm{P}<0.005 \mathrm{Rr}=1.9$. De las de parto pretérmino, el $17.7 \%$ tenían cónyuge con estabilidad laboral y de término el $42.5 \%$. $\mathrm{X}^{2}=90.1 \mathrm{P}<0.005$. En $21.9 \%$ de pretérmino y $13.5 \%$ de término el cónyuge se dedicaba a labores campesinas, todas estas pacientes residían en área rural.

ACTIVIDAD LABORAL MATERNA. Realizaban únicamente actividades propias de su hogar $658(86.2 \%)$ de las que tuvieron parto pretérmino y $694(90.9 \%)$ de las de término. $105(13.8 \%)$ de pretérmino y $69(9.1 \%)$ de término cumplían actividad laboral fuera del hogar. $\mathrm{X}^{2}=8.2 \mathrm{P}<0.005 \mathrm{Rr}=$ 1.6. Con labores menores de 8 horas diarias existió predominio de pacientes de término. Con labores superiores a 8 horas diarias, generalmente servicio doméstico, predominaron las pacientes de pretérmino. $\mathrm{X}^{2}=22.7 \mathrm{P}<0.005 \mathrm{Rr}=$ 4.6 (Gráfica 4).

NúMERO DE GESTACIONES (Gráfica 5). El 42.2\% de las pacientes que tuvieron parto pretérmino eran primigestantes. El 21.2\% cursaban su segunda gestación. La frecuencia de parto pretérmino fue disminuyendo a medida que aumentaban los embarazos, para experimentar un ligero incremento cuando la embarazada tenía seis o más gestaciones.

ANTECEDENTES DE ABORTOS (Gráfica 6). Descontando las 322 pacientes primigestantes, tenemos una población de 441 pacientes que habían tenido más de un embarazo. Entre aquellas con parto pretérmino el $52.3 \%$ no tenían antecedente de aborto, y tampoco lo tenían el $82.2 \%$ de las de
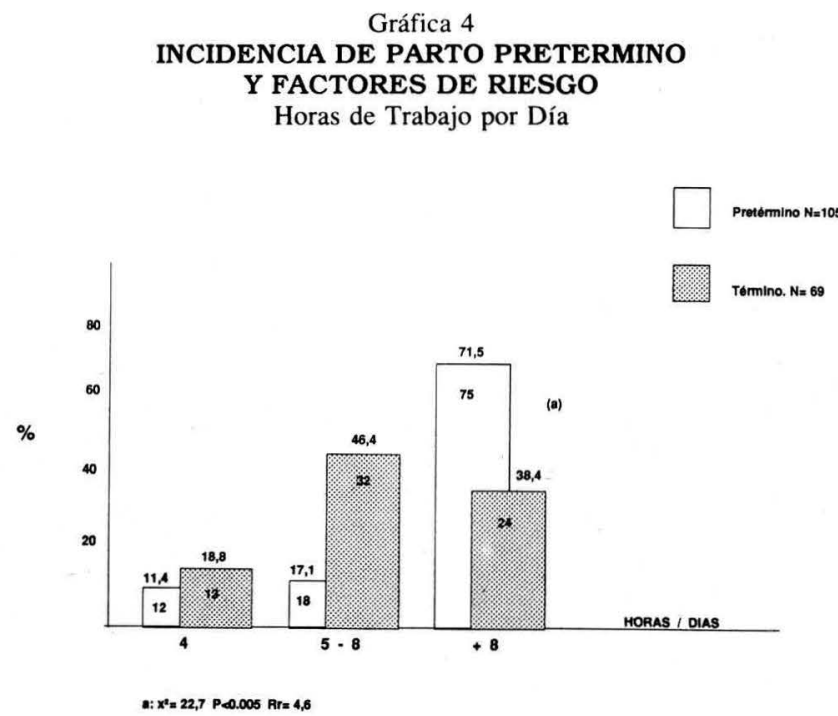
Gráfica 5

INCIDENCIA DE PARTO PRETERMINO

Y FACTORES DE RIESGO

Número de Embarazos

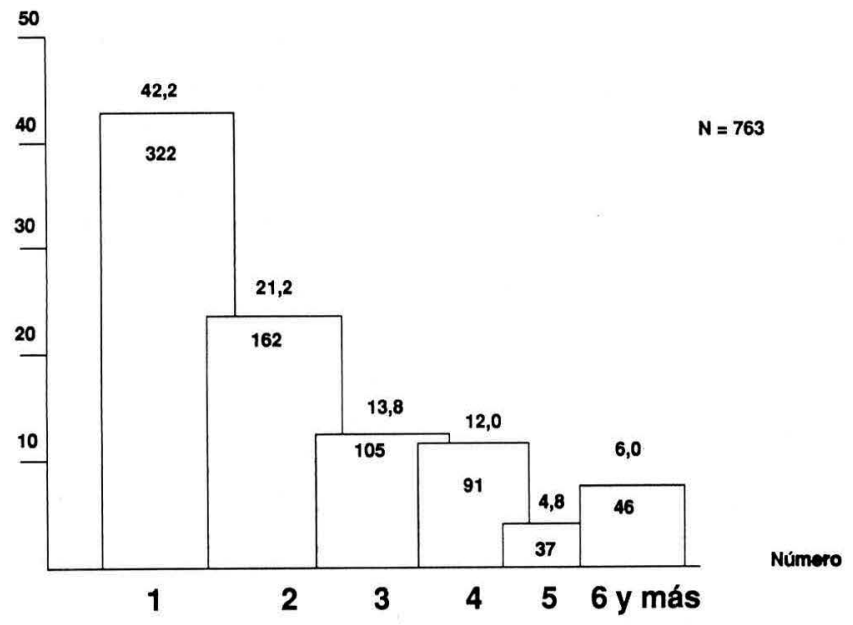

término. 210 de pretérmino y 74 de término tenían antecedente de aborto. $\mathrm{X}^{2}=95.8 \mathrm{P}<0.005 \mathrm{Rr}=4.5$. Un aborto tenían el $32.0 \%$ de las de pretérmino frente al $6.3 \%$ de las de término.

ANTECEDENTE DE PARTO PREMATURO (Gráfica 7). El $65.3 \%$ de las pacientes de pretérmino no tenían antecedentes de parto pretérmino en gestación anterior, tampoco el $80.4 \%$ de los de término. 153 de pretérmino y 69 de término tenían dicho antecedente. $X^{2}=42.2 \mathrm{P}<0.005 \mathrm{Rr}=2.8$. Desglosando, según el número de partos prematuros previos siempre las pacientes con parto pretérmino predominaron sobre las de término.

CONTROL PRENATAL (Tabla 2). El 78.4\% de los casos no tenía revisión prenatal, tampoco el $29.9 \%$ de los controles. $\mathrm{X}^{2}=358 \mathrm{P}<0.005 \mathrm{Rr}=8.5$. Habían asistido a control prenatal 165 de las que tuvieron parto pretérmino, acudiendo 112 una sola vez, 20 a dos o tres consultas y sólo el $20.1 \%$ a más de cuatro consultas. Por otro lado, las de término, 199 acudieron a un control y el $38.6 \%$ a más de cuatro consultas (Gráfica 8). Con un solo control prenatal hay un marcado predominio de pacientes con parto de pretérmino.

Tabla 2

INCIDENCIA DE PARTO PRETERMINO Y FACTORES DE RIESGO Control Prenatal

\begin{tabular}{|ccccc|}
\hline \multirow{2}{*}{$\begin{array}{c}\text { Control } \\
(*)\end{array}$} & \multicolumn{2}{c}{ Pretérmino } & \multicolumn{2}{c|}{ Término } \\
\cline { 2 - 5 } & Número & $\%$ & Número & $\%$ \\
\hline No & 598 & 78.4 & 228 & 29.9 \\
Sí & 165 & 21.6 & 535 & 70.1 \\
\hline TOTAL & 763 & 100 & 763 & 100 \\
\hline
\end{tabular}

$* \mathrm{X}^{2}=358 \mathrm{P}<0.005 \mathrm{Rr}=8.5$

Monterrosa: $89-131$
Gráfica 6

INCIDENCIA DE PARTO PRETERMINO

Y FACTORES DE RIESGO

Antecedente de Abortos

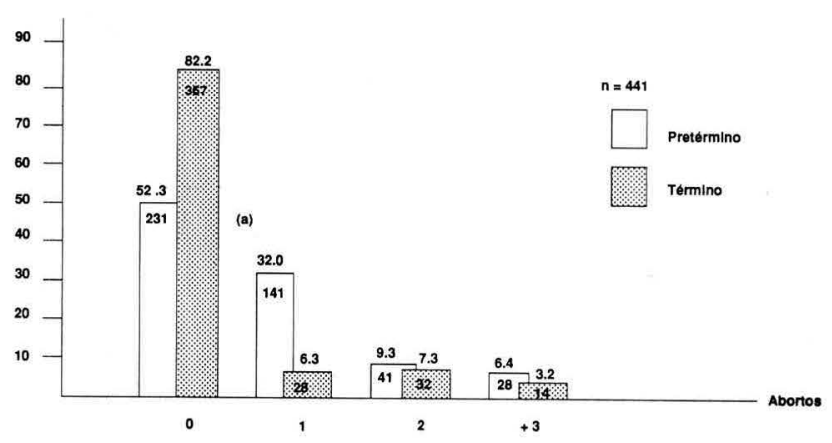

(a) : $x^{2}=95.8 \quad P<0.005$ R $r=4.5$

Esto se invierte cuando acudieron a revisión prenatal entre dos y cinco veces.

HÁBITO DE FUMAR. Sólo el $10.1 \%$ (77) de las pacientes de pretérmino y el $5.5 \%$ (42) de las de término tenían el hábito de fumar. $\mathrm{X}^{2}=11 \mathrm{P}<0.005 \mathrm{Rr}=1.9$. La Gráfica 9 presenta desglosado el número de cigarrillos fumados por días por estas pacientes. Cuando se consumían menos de 3 cigarrillos por día es notorio el predominio de los partos de término; de cuatro en adelante hay predominio de los de pretérmino $(67.5 \%)$ sobre los de término $(47.6 \%) . \mathrm{X}^{2}=$ $4.3 \mathrm{P}<0.05 \mathrm{Rr}=2.2$.

PRESENTACION FETAL Y VIA DEL PARTO (Tabla 3). El $87.5 \%$ de los fetos (700) estaban en cefálica. El $12.1 \%$ (96) en podálica y $4(0.4 \%)$ en transversa. Los 4 fetos en transversa eran embarazos únicos y fueron obtenidos por cesárea. De los cefálicos el $75.7 \%$ fueron obtenidos por vía vaginal y el $24.3 \%$ restante por cesárea. En podálica el $60.4 \%$ por cesárea y el $39.6 \%$ por ruta natural. Los trillizos se obtuvieron por cesárea al igual que el $80 \%$ de los geme-

\section{Gráfica 7 \\ INCIDENCIA DE PARTO PRETERMINO Y FACTORES DE RIESGO \\ Antecedente de Parto Prematuro}

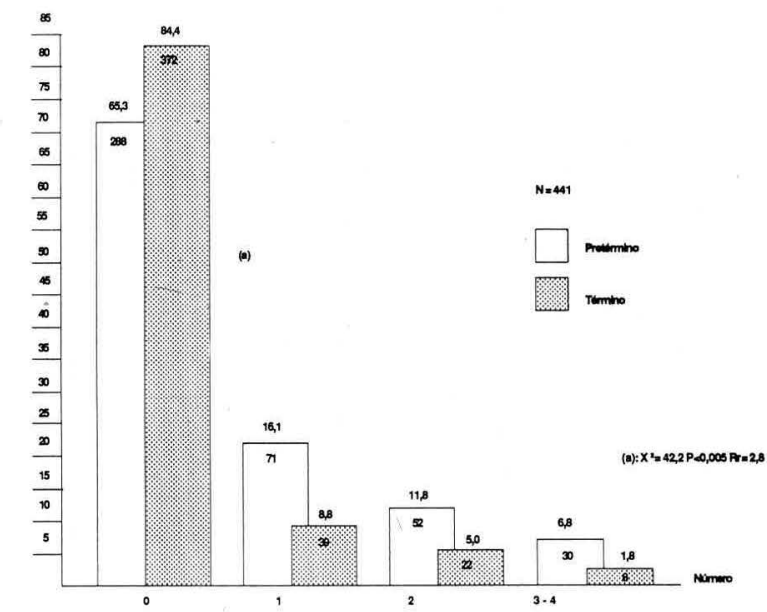




\section{Gráfica 8 \\ INCIDENCIA DE PARTO PRETERMINO Y FACTORES DE RIESGO \\ Control Prenatal}

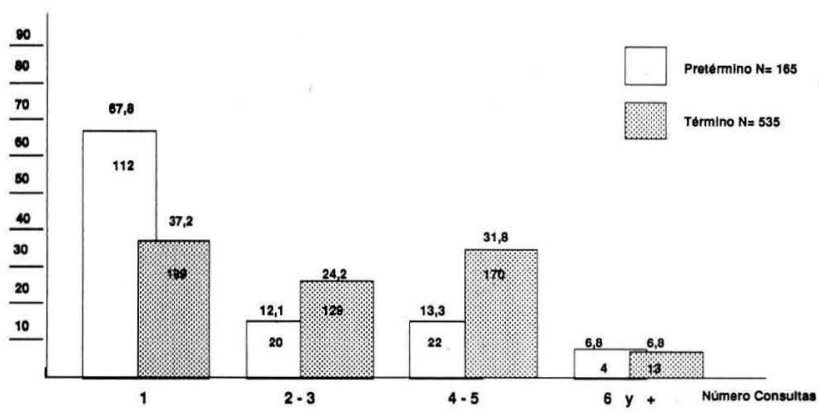

lares. Igual vía se eligió siempre que el primer feto se encontrase en podálica.

APGAR AL NACER (Gráfica 10). Descontando los 92 pretérminos y los 32 de término que nacieron obitados, tenemos que al primer minuto el $71.7 \%$ (507) de los pretérmino tenían apgar igual o mayor de 7 , en tanto que el $82.4 \%$ de término (628) tenían igual cifra. Menos de 7 tenían 201 (28.3\%) de los prematuros y $134(17.6 \%)$ de los maduros. $\mathrm{X}^{2}=24 \mathrm{P}<0.005$. Al quinto minuto con apgar inferior a 7 estaban $125(17 \%)$ de los de pretérmino y $66(8.7 \%)$ de los de término. $\mathrm{X}^{2}=114 \mathrm{P}<0.005$.

PESO FETAL Y EDAD GESTACIONAL (Tabla 4). El 90.9\% de los recién nacidos con 34-36 semanas de gestación pesaban entre 1.501-2.500 gramos. El 9.1\% tuvo un peso superior a 2.500 gramos. Si el embarazo tenía 31-33 semanas el $98.1 \%$ tuvo menos de 2.500 gramos de peso. El $87.2 \%$ tuvo menos de 1.500 gramos de peso si la edad gestacional era entre 28 y 30 semanas. En este rango de edad, el $31.9 \%$ tenían menos de 1.000 gramos de peso al nacer.

\section{Comentarios}

La incidencia de parto pretérmino en el año de 1988 fue de $7.3 \%$, cifra sorprendentemente baja para una población de escaso nivel socio-económico-cultural, la cual procede de la periferia de Cartagena y áreas rurales circundantes. Schwarcz, et al. (41) establecieron para América Latina una frecuencia de bajo peso al nacer del $9 \%$ y Alfonso Jubiz en el texto integrado de obstetricia informa una frecuencia del 10.6\% para 1982 en la Fundación Hospitalaria San Vicente de Paúl, Medellín, Colombia.

Similar a lo informado por Fernando Arias, et al. (1), la frecuencia de operación cesárea se incrementó del $17.3 \%$ en la totalidad de la población, al $26.1 \%$ en el manejo del parto pretérmino. Así mismo se aumentó la frecuencia de presentación podálica alcanzando el $12.1 \%$. La frecuencia de presentación podálica para la totalidad de la población es del $3.1 \%$ en esta institución (Conducta obstétrica ante presentación podálica, Monterrosa Castro Alvaro, inédito).

En el $33.1 \%$ no se encontró patología asociada a la gestación, circunstancia definida como parto pretérmino idiopático. En otro estudio colombiano (20) informan el 70\%, Arias, et al. (1) $29.8 \%$, Amon (6) $20.5 \%$. El parto pretérmino idiopático puede estar en relación con factores ambientales y características maternas (27).
Tabla 3

INCIDENCIA DE PARTO PRETERMINO Y FACTORES DE RIESGO

Presentación Fetal y Vía del Parto

\begin{tabular}{|ccccc|}
\hline $\begin{array}{c}\text { Vía } \\
\text { del } \\
\text { Parto }\end{array}$ & Cefálica & Podálica & Transversa & Total \\
\cline { 2 - 4 } & Presentación Fetal \\
\hline Cesárea & $170(24.3 \%)$ & $58(60.4 \%)$ & $4(100 \%)$ & 232 \\
Vaginal & $530(75.7 \%)$ & $38(39.6 \%)$ & -- & 568 \\
\hline TOTAL & $700(87.5 \%)$ & $96(12.1 \%)$ & $4(0.4 \%)$ & 800 \\
\hline
\end{tabular}

Monterrosa: 89-129

La ruptura de membranas amnióticas, antes del inicio del trabajo de parto, se ha correlacionado con disminución en la elasticidad de las mismas y a un deficiente estado nutricional materno (33). La ruptura prematura de membranas es la primera causa de parto pretérmino. Naeye Richard $(33,38,39)$ es uno de los autores que más ha estudiado este evento que aumenta significativamente la morbi-mortalidad perinatal (32). El líquido seminal, el coito, el hábito de fumar, la incompetencia cervical, la infección y la inflamación aguda del tracto genital han sido considerados factores que favorecen la ruptura de las membranas ovulares $(28,33,38,39)$. La instalación temprana de actividad uterina es otra posibilidad $(17,18,19)$. El examen pélvico en el último trimestre puede inocular bacterias en el canal cervical favoreciendo la ruptura prematura de membranas, sostiene Lenihan (32). Se encontró que el $22.9 \%$ de las pacientes que tuvieron parto pretérmino tenían ruptura prematura de membranas. Arias (1) informa el $34.9 \%$ y Amon (6) $14.3 \%$.

En sólo 3\% de las pacientes pudo demostrarse corioamnionitis, la cual era evidente clínicamente. La colonización de la cavidad amniótica suele ocurrir después de rotas las membranas (37). Algunos autores citados por Wahbeth (36) han encontrado colonización de la cavidad amniótica estando las membranas íntegras. La frecuencia de la corioamnionitis subclínica sin ruptura de membranas en el trabajo de parto pretérmino ha sido considerada del 21 al 48\% (35). Diversas bacterias y la candida Albicans han sido aisladas en líquido amniótico de pacientes asintomáticas, recurriendo a la amniocentesis (35). El papel cie la colonización de las membranas amnióticas y la corioamnionitis subclínica sin ruptura de membranas, en la etiología del parto prematuro está por resolverse, aunque se han correlacionado con un pobre éxito neonatal (37). Hay controversia en cuanto a la relación entre Chlamydea trachomatis, Mycoplasma Hominis y Ureaplasma Urealyticum con ruptura prematura de membranas y parto pretérmino.

Infección urinaria fue la segunda patología en frecuencia asociada al parto pretérmino, correspondiéndole el $13.2 \%$. El estudio colombiano a que se ha hecho referencia (20) determinó el $16.5 \%$. Está establecido que la infección urogenital puede jugar papel en la etiología del parto prematuro (4). La migración de bacterias desde el árbol urinario puede colonizar la cavidad vaginal, el canal cervical y las membranas amnióticas, con el riesgo de ruptura prematura de membranas y parto pretérmino, según lo establecido por Naeye 
Gráfica 9

INCIDENCLA DE PARTO PRETERMINO

Y FACTORES DE RIESGO

Hábito de Fumar

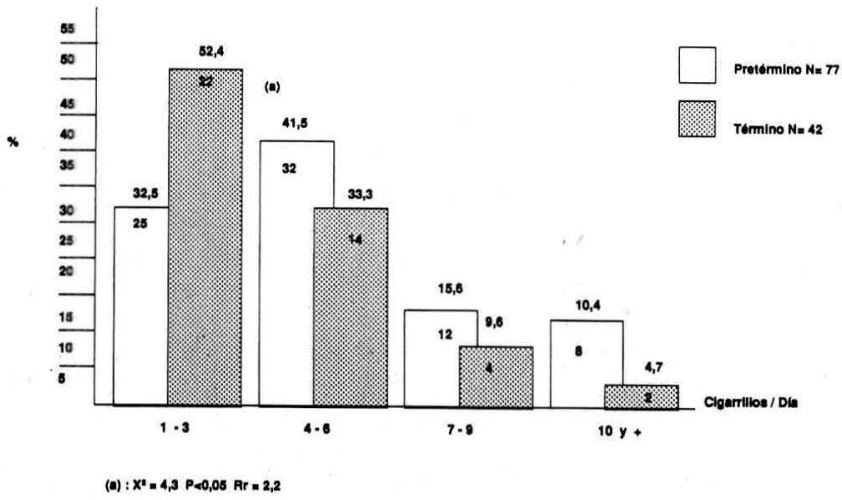

$(38,39)$. Pielonefritis puede desencadenar parto prematuro por los efectos indirectos de la fiebre $(22,40)$. La bacteriuria asintomática puede tener relación de causa con la prematurez y su tratamiento disminuirá la tasa de parto prematuro.

El parto pretérmino está correlacionado con placenta previa y desprendimiento prematuro placentario. En el $14.7 \%$ de la población estudiada se encontraron dichas complicaciones obstétricas. Amon (6) informa 20.3\%. Chamberlain (22) señala que la placenta previa es una causa que puede producir parto pretérmino. En un estudio por él realizado encontró que el $35 \%$ de los desprendimientos prematuros de placenta suceden antes de las 37 semanas. Emile Papiernik $(12,13$, 40) considera que el sangrado genital aumenta significativamente la tasa de prematurez y establece un riesgo relativo tres veces mayor cuando se ha observado sangrado, que en embarazos en que ha estado ausente. Historia de sangrado en la gestación es un importante valor de predicción del parto pretérmino (40).

Geoffrey Chamberlain (22) cita un estudio que establece que la duración del embarazo gemelar es de 261 días, el triple de 246 , frente a los 280 del embarazo único y considera que la mitad de los embarazos múltiples terminan antes de las 37 semanas. Si bien son mal entendidos los mecanismos del inicio del trabajo de parto (2), se considera que el acor-

Tabla 4

INCIDENCIA DE PARTO PRETERMINO Y FACTORES DE RIESGO

Edad Gestacional y Peso al Nacer

\begin{tabular}{|crrrrr|}
\hline & \multicolumn{5}{c|}{ Pesoal Nacer } \\
\cline { 3 - 6 } $\begin{array}{c}\text { Edad } \\
\text { Gestacional }\end{array}$ & $<1.000$ & $1.001-1.5001 .501-2.500$ & $>2.500$ & Total \\
\hline $28-30$ & $42(31.9 \%)$ & $73(55.3 \%)$ & $17(12.8 \%)$ & -- & 132 \\
$31-33$ & $8(2.5 \%)$ & $121(38.7 \%)$ & $178(56.9 \%)$ & $6(1.9 \%)$ & 313 \\
$34-36$ & $1(0.4 \%)$ & $27(10.3 \%)$ & $211(88.2 \%)$ & $24(9.1 \%)$ & 263 \\
\hline TOTAL & 51 & 221 & 406 & 30 & 708 \\
\hline
\end{tabular}

Monterrosa: $89-130$
Gráfica 10

\author{
INCIDENCIA DE PARTO PRETERMINO \\ Y FACTORES DE RIESGO \\ Test de Apgar
}

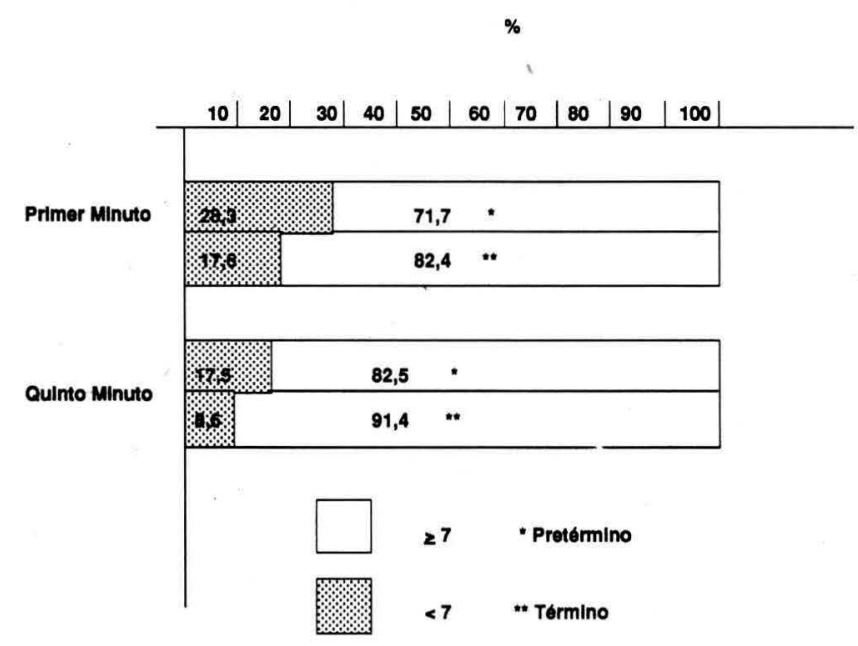

tamiento se debe a la sobredistensión uterina, a la presencia de una masa placentaria mayor y una mayor producción hormonal, con niveles superiores de estrógenos que facilitarían un inicio temprano de la contractilidad uterina (22). Embarazo múltiple se encontró en el $4.7 \%$ de los partos pretérmino. Arias (1) señala en su estudio el $15.2 \%$. Los embarazos gemelares son una causa directa de la sexta parte de los partos pretérmino, indica Papiernik (40). Otros autores (4) consideran del 5 al $10 \%$. Para prevenir el desencadenamiento del trabajo de parto pretérmino en gestaciones múltiples es importante su diagnóstico temprano, el adecuado seguimiento y es de valor el uso de los betamiméticos orales (30). El polihidramnios por la sobredistensión uterina puede desencadenar contractilidad, favoreciendo a su vez la ruptura prematura de membranas. No se debe olvidar la correlación con malformciones congénitas fetales (40). En el $2.3 \%$ se evidenció polihidramnios.

El estudio ha señalado que las pacientes menores de 18 años y mayores de 36 tienen un riesgo relativo de parto pretérmino de tres y dos respectivamente, evento plenamente demostrado en la literatura. Se ha demostrado que el embarazo en la adolescencia entraña un mayor riesgo de parto pretérmino, bajo peso al nacer y muerte perinatal (5). Las razones no han sido claramente establecidas y se ha llegado a enunciar como causales la inmadurez física y las implicaciones socio-educativo-culturales que llevan a un control prenatal inadecuado y a una inestabilidad síquica producto de la falta de apoyo familiar o social (21). Papiernik (40) sostiene que en las pacientes adolescentes que son protegidas del aislamiento moral y social, y el embarazo es controlado adecuadamente, se disminuyen notablemente las tasas de parto pretérmino. Este mismo autor en sus programas de prevención $(8,11,12,13)$ ha puesto énfasis en los hábitos y circunstancias de vida de la mujer embarazada. El estrés debido a condiciones socio-económicas adversas es uno de los factores de riesgo que acompañan al parto pretérmino. El parto prematuro es también una entidad social (40). La desnutrición, el analfabetismo y las bajas condiciones sani- 
tarias han sido analizadas. En el estudio se encontró un riesgo relativo de dos para parto pretérmino cuando la paciente residía en área rural, mas no hubo diferencia estadísticamente significativa de acuerdo al nivel educativo. La inestabilidad del hogar ha sido también implicada. Se encontró una mayor incidencia de prematurez entre pacientes abandonadas por el cónyuge. El mayor número de partos de término fue obtenido en mujeres casadas o en unión libre estable. Papiernik (40) consigna que las pacientes solteras pueden estar inseguras en el deseo del embarazo, quieren esconderlo del ambiente social, tienen dieta pobre, generalmente menor acceso a información y un inadecuado control prenatal.

La inestabilidad económica, producto de la falta de actividad laboral del cónyuge, es otro factor social de riesgo. El estudio presenta una población con alta incidencia de desempleo o actividad laboral inestable en los cónyuges. En estas condiciones estaban el $60 \%$ y el $44 \%$ de las pacientes de pretérmino y de término respectivamente, estableciéndose riesgo relativo de 1.9 .

Controvertidas son las afirmaciones acerca de la actividad laboral materna y parto pretérmino $(13,22,24,25,26,40)$. En el presente estudio se encontró un bajo porcentaje de pacientes que cumplían actividad fuera del hogar, generalmente en servicio doméstico. Sin embargo fue estadísticamente significativa la diferencia y el riesgo relativo fue de 1.6. Cuando las labores pasaban de ocho horas diarias el $\mathrm{Rr}$ ascendía a 4.6. Existe íntima relación entre trabajo físico pesado y parto pretérmino. Papiernik (40) sustenta que los esfuerzos físicos, caminar rápido, trabajo doméstico y cargar niños, pueden inducir el inicio de actividad uterina. Mamelle (26) ha publicado diversos estudios al respecto y ha establecido índices para evaluar el riesgo de parto pretérmino en gestantes con actividad laboral. Murphy, et al. (24) sostienen que la embarazada saludable, sin historia médica u obstétrica patológica, puede continuar laborando durante la gestación.

La gestante que no ha tenido parto es tres veces más propensa de tener amenaza de parto prematuro (20). El estudio señaló que el $40 \%$ de las pacientes que presentaron parto pretérmino cursaban su primera gestación. La multiparidad, mayor de cuatro embarazos, es un factor importante en los índices de predicción establecidos $(11,13)$. El parto prematuro previo y el aborto previo son factores de predicción valiosos $(22,27,40)$. En el presente estudio el $\mathrm{Rr}$ de parto pretérmino con aborto previo fue del 4.5 y de 2.8 con antecedente de parto prematuro. Roy A. Carr-Hill (27) en un amplio estudio analítico sobre la repetición del parto prematuro espontáneo afirma que el riesgo de parto pretérmino en el segundo embarazo es más del triple, de 4 a $15 \%$, si el parto anterior fue pretérmino. Dos pretérminos previos elevan el riesgo al $32 \%$. En este mismo estudio (27) la evaluación del aborto previo no arrojó resultados indicativos de riesgo a diferencia de otros autores.

La falta de control prenatal aumenta la morbi-mortalidad materna y perinatal $(3,5,7,23)$. Es muy deficiente la cobertura de control prenatal en nuestro medio. El $78 \%$ de los casos y el $30 \%$ de los controles no habían consultado durante la gestación, cifras altamente preocupantes. El control prenatal suele considerarse adecuado cuando la paciente ingresa durante el primer trimestre de gestación y consulta con suficiente frecuencia. Es inadecuado cuando ingresa en el segundo o tercer trimestre o consulta irregularmente (5). Comparando los resultados, observamos cómo la mayoría de las pacientes de pretérmino no tenían control prenatal o tenían una sola consulta. Cuando las consultas fueron más de dos predominan las de término, lo cual coincide con lo expuesto por Theresa Scholl (5), quien sostiene que el parto pretérmino se reduce en la proporción en que aumenta el control prenatal, y probablemente el control adecuado afecta el peso al nacer, ante todo por la ganancia de peso materno. Greenberg (23) realizó un amplio estudio evaluando el impacto del control prenatal en diferentes grupos sociales, y estableció la gran influencia que ejercen los factores sociales en el bajo peso al nacer correlacionados con el control prenatal deficiente. El control prenatal debe ser de buena calidad, lo que implica el análisis de los diferentes factores de riesgo y la detección temprana de la actividad uterina y de los cambios cervicales. Emile Papiernik $(8,40)$ sostiene que es posible encontrar cambios cervicales semanas antes del inicio de la actividad uterina. La evaluación del cervix uterino en cada consulta prenatal es un proceder controvertido $(14,15,16,31,32,40)$. Gonik y Creasy $(2,14)$ sostienen que la evaluación del cervix no incrementa los riesgos iatrogénicos, mientras Main, et al. $(15,16)$ sostienen que la exploración cervical eleva el riesgo de infección del canal cervical con la posibilidad de ruptura de membranas y parto prematuro. Igual concepto sostiene Naeye $(33,39)$ con relación al coito. Main, et al. $(15,16)$ han cuestionado los índices para detectar el riesgo de parto pretérmino establecidos por Papiernik y Creasy, están en desacuerdo con la exploración cervical y no han encontrado disminución en la incidencia de parto prematuro. Por su parte Stubbs y col. (31) realizan evaluación cervical como medio de determinar el riesgo de parto pretérmino e informan que cuando la dilatación es superior a un centímetro y el borramiento superior al 40\%, el $\mathrm{Rr}$ de parto pretérmino es de 4.2; finalizan estableciendo los beneficios de la evaluación cervical rutinaria. Debe realizarse diagnóstico temprano de la incompetencia cervical y realizarse el cerclaje cervical. Estas pacientes deben considerarse de más riesgo a parto pretérmino y ruptura prematura de membranas, y no salvadas del riesgo de prematurez. La instalación de actividad uterina en forma temprana puede ser seguida por parto pretérmino (8). Hoy en día en medios desarrollados se usan monitoreos ambulatorios para documentar la presencia de actividad uterina en pacientes con riesgo de parto pretérmino. Los beneficios de este recurso tecnificado han sido informados por Katz, Newman, et al. $(17,18,19)$.

Es poco frecuente el hábito de fumar entre el grupo de mujeres que acuden al Hospital de Maternidad Rafael Calvo. Se ha informado la relación existente entre bajo peso al nacer, parto pretérmino y el hábito de fumar, sobre todo cuando el consumo es asociado a café y alcohol $(22,28)$. En el control prenatal debe desestimularse el consumo de cigarrillo por la paciente gestante (28). Aunque se considera que la nicotina con su efecto vasoconstrictor influye negativamente en el feto y su crecimiento, no están todavía plenamente estudiados los factores biológicos, ambientales y sicológicos que influyen en las embarazadas.

El $75.7 \%$ de los fetos cefálicos pretérminos nacieron vía vaginal y el $60.4 \%$ de los podálicos se obtuvieron por cesárea. Ha sido debatida la vía adecuada para obtener el recién 
nacido pretérmino (42). Por ser la cabeza fetal relativamente mayor que el abdomen y tórax, existe el riesgo que los últimos crucen el cuello parcialmente dilatado y la cabeza sea atrapada con la consiguiente asfixia intraparto, cuando el feto está en presentación pelviana. Esto llevó a aconsejar cesárea para todo pretérmino en podálica. Posteriormente se demostró que la cesárea no evita el traumatismo fetal. Una incisión pequeña, mal localizada, y la contracción rápida del segmento uterino, pueden ser tan peligrosos como una dilatación incompleta (42). Se deben dejar las membranas intactas siempre que sea posible. Esto evita la compresión de la cabeza si el feto es cefálico y se disminuye el riesgo de hemorragia en el sistema nervioso central. Existen discusiones acerca de los riesgos y beneficios del uso del fórceps, la práctica de la episiotomía y el recurso de la cesárea. Watson A. Bowes (42) recuerda que el feto pretérmino es más frágil que el de término, que se deben aminorar las posibilidades de trauma y la vía del parto seleccionarla individualmente con miras a evitar la asfixia intraparto. Realizar una pronta y eficiente reanimación del recién nacido.

Aunque es baja en nuestro medio la incidencia de parto pretérmino, no deja de ser una situación de interés ya que constituye el mayor problema en medicina perinatal (16). Los agentes farmacológicos introducidos para el tratamiento de la amenaza de parto pretérmino no han cambiado la incidencia (14). Son múltiples los factores que intervienen para que la gestación llegue a su fin mucho antes de lo normal. Estos factores de riesgo no intervienen en forma aislada, generalmente se asocian y en sumatoria aumentan las posibilidades de morbilidad y mortalidad. Muchos de estos factores adversos pueden ser corregidos ejecutando progrmas de predicción y prevención. Papiernik en la evaluación más amplia publicada, el estudio de Haguenau, Francia (11), concluye: "se presenta una notable reducción en el parto pretérmino y en el bajo peso al nacer cuando un programa de prevención es adelantado".

\section{Conclusiones}

1. Incidencia de parto pretérmino: $7.3 \%$.

2. Parto pretérmino idiopático: $33.1 \%$.

3. Primera causa de parto pretérmino: ruptura prematura de membranas, $22.9 \%$.

4. Segunda causa: infección urinaria, $13.2 \%$.

5. En $14.7 \%$ existió necesidad de cesárea por existencia de desprendimiento placentario o placenta previa sangrante.

6. Embarazo múltiple: $4.7 \%$.

7. Adolescentes: riesgo relativo de parto prematuro, tres veces.

8. Mayores de 36 años: riesgo relativo dos veces mayor.

9. Area rural de residencia: riesgo relativo dos veces mayor.

10. No se encontró diferencia significativa según nivel educativo.

11. $21.2 \%$ de pacientes de parto prętérmino y $15.7 \%$ de término estaban abandonadas por el cónyuge. $\mathrm{P}<0.01$.

12. Desempleo del cónyuge, riesgo relativo $=1.9$.

13. Actividad laboral materna, $\mathrm{Rr}=1$.9. Actividad mayor a ocho horas diarias el $\mathrm{Rr}$ asciende a 4.6.

14. $40 \%$ de las pacientes fueron primigestantes.

15. Más de cuatro gestaciones tenían el $20 \%$.

16. Parto prematuro previo, $R r=2.8$. Aborto previo, $R r=4.5$.

17. Deficiente cobertura de atención prenatal. Sin control: $78 \%$ de los casos y $30 \%$ de los controles. $\mathrm{Rr}=8.5$.

18. Hábito de fumar: $\mathrm{Rr}=2.2$ cuando el consumo fue superior a cuatro cigarrillos por día.

19. $60.4 \%$ de podálicos nacieron por cesárea. $75.7 \%$ de cefálicos por vía vaginal.

\section{BIBLIOGRAFIA}

1. Arias F, Tomich P. Etiology and outcome of low birth and preterm infants. Obstet Gynecol 1982; 60(3): 277-281.

2. Gonik B, Creasy RK. Preterm labor: its diagnosis and management. Am J Obstet Gynecol 1986; 154(1): 3-8.

3. Aller MC, Jones MD. Medical complication of prematury. Obstet Gynecol 1986; 67(30): 427-437.

4. Howie PV, Patel NB. Manejo obstétrico del parto pretérmino. Ginecol Obstet; Temas actuales 1984; 4: 377-391.

5. Scholl TO, Miller LK, Salmon RW, et al. Prenatal care adequancy and the outcome of adolescent pregnancy: effects on weight gain, preterm delivery, and birth weight. Obstet Gynecol 1987; 69(3): 312-316.

6. Amon E, Anderson GD, Sibai BM, et al. Factors responsibe for preterm delivery of the inmature newborn infants. Am J Obstet Gynecol 1987; 156(6): 1143-1148.

7. Yin K, Fielder AR, Shaw DE, et al. Epidemiology of retinopathy of prematurity. Lancet II 1988; 1235-1238.

8. Papiernik E, Bouyer J, Collin D, et al. Precocious cervical ripening and pretterm labor. Obstet Gynecol 1986; 67(2): 238-248.

9. Castle BM, Turnbull AC. The presence or abscense of fetal breathing movements predicts the outcome of preterm labour. Lancet II 1983; 471-472.

10. Cole CH. Prevention of prematurity: can we do it in America? Pediatrics 1985 ; 76(2): 310-312.
11. Papiernik E, Bouyer J, Dreyfus J, et al. Prevention of preterm births: A perinatal study in Haguenau, France. Pediatrics 1985; 76(2): 154158.

12. Papiernik E, Maine D, Rush D, et al. Prenatal care and the prevention of preterm delivery. Int J Gynecol Obstet 1985; 23: 427-433.

13. Papiernik E, Bouyer J, Yaffe K. Womens acceptance of a preterm birth prevention program. Am J Obstet Gynecol 1986; 155(5): 939946.

14. Herron MA, Katz M, Creasy RK. Evaluation of a preterm birth prevention program: preliminary report. Obstet Gynecol 1982; 59(4): 452-456.

15. Main DM, Richardson D, Gabbe SG, et al. Prospective evaluation of a risk scoring system for predicting preterm delivery in block inner city women. Obstet Gynecol 1987; 69(1): 61-64.

16. Main DM, Gabbe SG, Richardson D, et al. Can preterm deliveries be prevented? Am J Obstet Gynecol 1985; 154(7): 892-898.

17. Katz M, Newman RB, Gill PJ, et al. Assessment of uterine activity in ambulatory patients at high risk of preterm labor and delivery. Am J Obstet Gynecol 1986; 154(1): 44-47.

18. Newman RB, Gill PJ, Wittreich P, et al. Maternal perception of prelabor uterine activity. Obstet Gynecol 1986; 68(6): 765-769.

19. Katz M, Gill PJ, Newman RB, et al. Detection of preterm labor by ambulatory monitoring of uterine activity: an preliminary report. Obstet Gynecol 1986; 68(6): 773-778. 
20. Pasmiño S. Parto prematuro en el ISS Valle. Informe preliminar. Rev Col Obst Ginecol 1984; 35(5): 363-367.

21. Horon IL, Strobino DM, MacDonald HM. Birth weights among infants born to adolescent and young adult women. Am J Obstet Gynecol 1983; 146(4): 444-449.

22. Chamberlain G. Epidemiología y etiología del niño pretérmino. Ginecol Obstet, Temas Actuales 1984; 4: 299-317.

23. Greenberg RS. The impact of prenatal care in different social groups. Am J Obstet Gynecol 1983; 145(7): 797-801.

24. Murphy JF, Dauncey M, Newcombe R. Employment in pregnancy prevalence, maternal characteristics, perinatal outcome. Lancet I 1984; 1163-1166.

25. Chamberlain G, García J. Pregnant women at work. Lancet I 1983; , 228-230.

26. Mamelle N, Muñoz F. Occupational working conditions and preterm birth: A realiable scoring system. Am J Epidemiology 1987; 126(1): 150-152.

27. Carr-Hill RA, Hall MH. The repetion of spontaneous preterm labour. British J Obst Gynecol 1985; 92: 921-928.

28. Dunn PM. Smoking and premature delivery (letter). Lancet I 1986; 1494.

29. Mazor M, Leiberman JR, Hagay ZJ. Delivery of premature twins (letter). Am J Obstet Gynecol 1986; 155(4): 915.

30. O'Leary JA. Prophilactic tocolysis of twins. Am J Obstet Gynecol 1985; 154(4): 904-906.

31. Stubbs TM, Van Dorsten PV, Miller III MC. The preterm cervix and preterm labor: relative risks, predictive values and change overtine. Am J Obstet Gynecol 1986; 155(4): 829-834.
32. Leninhan JP. Relationship of antepartum pelvic examinations to premature rupture of the membranes. Obstet Gynecol 1984; 63(1): 33-37.

33. Naeye RL. Factor that predispose to premature rupture of the fetal membranes. Obstet Gynecol 1982; 60(1): 93-98.

34. Mac Guillivray I, Davey DA. The influence of fetal sex on rupture of the membranes and preterm labor. Am J Obstet Gynecol 1985; 153(7): 814-815.

35. Gravett MG, Hummel D, Eschenbach DA, et al. Preterm labor associated with subclinical amniotic fluid infection and with bacterial vaginosis. Obstet Gynecol 1986; 67(2): 229-237.

36. Wahbeth CJ, Hill GB, Eden RD, et al. Intra amniotic bacterial colonization in premature labor. Am J Obstet Gynecol 1984; 148(6): 739-743.

37. Hillier SL, Martins J, Hrohn M. et al. A case-control study of chorioamniotic infection and histologic chorioamnionitis in prematurity. N Engl J Med 1988; 319: 972-978.

38. Naeye RL, Peters EC. Causes and consequences of premature rupture of the membranes. Lancet I 1980; 192-194.

39. Naeye RL. Coitus and associated amniotic fluid infections. N Engl J Med 1979; 301: 1198-1199.

40. Papiernik E. Predicción del parto pretérmino. Rev Galénica 1987; 1(5): 179-199.

41. Schwarcz R, Díaz AG, Fescina R, et al. El bajo peso al nacer y la mortalidad perinatal en maternidades de América Latina. En: Salud materno-infantil y atención primaria en las Américas. Publ Cientif OPS 1984; 461: 105-117.

42. Bowes WA. Tratamiento clínico del parto pretérmino. Clin Obstet Ginecol 1988; 3: 629-636.

\section{INFORME CONGRESOS}

XIII CONGRESO MUNDIAL DE OBSTETRICIA Y GINECOLOGIA. Figo 1991, del 15 al 20 de septiembre de 1991, Singapur. Informes e inscripciones:

Dr. P.C. WONG.

Secretario General del Comité Organizador, O. \& G., Society of Singapure. C/O/Dept. of Obstetrics \& Gynaecology. National University Hospital. Lower Kent Ridge Road. Singapore 0511. Republic of Singapore. Tel. (65) 3382154/3382314. Telefax: (65) 3382351. Télex: UNISPO RS 33943.

II ${ }^{\text {nd }}$ WORLD CONGRESS FOR INFECTIOUS DISEASES IN OBSTETRICS AND GYNECOLOGY. September 7th, -14 th, 1991 BANGKOK, THAILAND. Abstract forms, Registration forms and Information: The Secretary, $\mathrm{II}^{\text {nd }}$ World Congress for Infectious Diseases in OB/GYN, P.O.B. 7020 27, 8000 Munich 70, FRG. FAX 0049/89/7095/8884. 